\title{
Relationship between Working Memory, Auditory Perception and Speech Intelligibility in Cochlear crossuarh Implanted Children of Elementary School
}

\author{
Soheyla Talebi ${ }^{1 *}$, Ali Akbar Arjmandnia ${ }^{1}$
}

1. Department of Psychology of Exceptional Children, Faculty of Psychology \& Education Sciences, University of Tehran, Tehran, Iran.

Citation: Talebi S, Arjmandnia AA. Relationship between working memory, auditory perception and speech intelligibility in cochlear implanted children of elementary school. Iranian Rehabilitation Journal. 2016; 14(1):35-42. http://dx.crossref.org/10.15412/J.IRJ.08140106

: http://dx.crossref.org/10.15412/J.IRJ.08140106

\section{Article info:}

Received: 19 Oct. 2015

Accepted: 28 Jan. 2016

\section{Keywords:}

Memory, Speech perception (CAP), Speech production (SIR), Working memory test battery for children (WMTB-C), Cochlear implant

\section{A B S T RACT}

Objectives: This study examined the relationship between working and short-term memory performance, and their effects on cochlear implant outcomes (speech perception and speech production) in cochlear implanted children aged 7-13 years. The study also compared the memory performance of cochlear implanted children with their normal hearing peers.

Methods: Thirty-one cochlear implanted children with a mean age of 121.52 months $(\sim 10$ years $)$ and $\mathrm{SD}=19.946$ and 31 normal hearing children with a mean age 120.68 months $(\sim 10$ years) and $\mathrm{SD}=18.137$ participated in this study. Their memory performance was assessed by Working Memory Test Battery for Children (1), speech perception was measured by Categories of Auditory Performance (2), and their speech production was assessed by Speech Intelligibility Rating (3). Finally, the data were analyzed using SPSS through its descriptive variables MANOVA and Spearman Correlation Coefficient.

Results: A significant and positive correlation was observed between working memory performance and cochlear implant outcomes. In addition, the children using cochlear implants had poorer performance compared to their normal hearing peers.

Discussion: This study demonstrated that the memory performance of children using cochlear implants has a significant effect on their speech production.

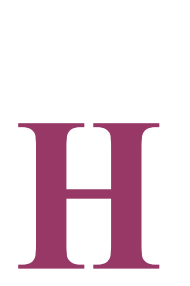

\section{Introduction}

earing is one of the superior senses of humans. Deprivation of hearing will result in missing not only the sounds around us but also the pleasant and encouraging experiences in the social life [4]. Hearing impairment affects language development and communication skills of children, followed by secondary cognitive and social symptoms. Timely measures and early actions including rehabilitative and training services at lower ages is the best method to minimize the negative effects of hearing impairment [5]. One of the most important problems in rehabilitation for those suffering from

\footnotetext{
* Corresponding Author:

Soheyla Talebi, MA

Address: Department of Psychology of Exceptional Children, Faculty of Psychology \& Education Sciences, University of Tehran, Iran.

Tel: +98 (913) 2246163

E-mail:s.talebi@ut.ac.ir
} 
hearing impairment is the issue of perception, especially auditory perception. Perception is a tool to acknowledge the peripheral world. The more complete and precise is the perception of human from its world, the more understanding it gains by his interaction with the world. Perception depends on the performances of physiological and neurophysiological systems that create a true or false mental image of the outside world. These systems act as tools for receiving and transferring the various types of information [6].

Auditory perception is a part of the perception that shows reception of physical motives created by the vibration of particles of an object in the material environment. Perception of rate, frequency, and features of sounds conduce recognition of their quantities and qualities, as well as their origins and concepts. Generally, auditory perception includes speech and non-speech sounds. Understanding speech is the best and most complex level of auditory perception that transfers concepts to a receiver [7]. The health of the auditory and nervous systems and brain affects the perception of received messages. Hence, hearing impairments affect auditory perception and speech intelligibility [6].

Hence, speech is an essential requirement of social life, and one requires fully functional senses as well as a rich environment full of speech to learn it. There are many prerequisites for gaining full mastery of speech, but hearing is the most important one. Therefore, it is obvious that the production of speech and its intelligibility in children is influenced by hearing impairments and faults. One of the most important factors for auditory perception and speech production is memory. Shortterm memory and working memory are the two important parts of cognitive processes focused by many researchers because of their importance. Working memory is a system for saving and manipulating data temporarily to protect cognitive activities for concurrent processing and saving data, whereas short-term memory is defined as a system to save trivial data for a short period. Studies about memory have attracted a great deal of scientific and lab studies in determining cognitive behavior [8].

Reviewing the history of the related literature, Chin et al. [9] studied speech intelligibility and prosody production in cochlear implanted children. In this study, two speech intelligibility tests, Beginner's Intelligibility Test (BIT) and Prosodic Utterance Production (PUP) were administered to 15 cochlear implanted children and 10 children with normal hearing. Percent correct scores were higher for intelligibility than for prosody and higher for children with normal hearing than for chil- dren with cochlear implants. Predicative sentences were recognized easily rather than the interrogative sentences and had the lowest rank in the spectrum. The findings suggested that the development of speech intelligibility progresses ahead of prosody in the children with cochlear implants and those with normal hearing; however, children with normal hearing still perform better than those with cochlear implants on measures of intelligibility and prosody even after accounting for hearing age.

Ibertson et al. [10] studied between speech recognition, working memory and conversational skills in a group of 13 children/adolescents with cochlear implants (CIs) between 11 and 19 years of age. They found a significant correlation between speech recognition and conversation skills. Moreover, the participants with better-working memory capacity used more requests for confirmation of new information (i.e. made more suggestions of their own) and fewer requests for confirmation of already given information compared to the participants with poorer working memory. It thus seems as if both speech recognition and working memory contribute to conversational skills but in different ways.

William and Libert [11] studied the phonological shortterm memory (pSTM) in cochlear-implanted children and examined the phonological similarities, work length, and lip-reading lines in those children. Their results showed that, compared to their age-matched hearing controls, cochlear-implanted children exhibited delayed development of their pSTM capacity, and exhibited reduced effect of phonological similarity and word length.

In a study by Philips et al. [12], 117 cochlear-implanted children in clinics of England, Iran, and Turkey were evaluated during a period of 5 years and at different intervals. Significant progress for auditory performance and speech intelligibility was reported as measured by two tools of Categories of Auditory Performance (CAP) and Speech Intelligibility Rating (SIR). The results showed that children that were implanted sooner had higher scores in both scales.

The results of two other studies by Dawson et al. [13] showed that cochlear-implanted children had weaker performances in short-term and working memory, but they reacted normally to tasks related to visual memory. In this study, auditory short-term memory was evaluated by tasks with the lowest linguistic requirement. As expected, children using cochlear implants showed poorer sequential short-term memory skills than their normal hearing peers for tasks that invited verbal coding. However, they performed similar to their hearing peers on 
auditory and visual memory tasks where the stimuli were less likely to be encoded verbally. The children using cochlear implants did not appear to have a deficit in shortterm memory specific to the auditory modality. The difference scores (visual minus auditory performance) for the implanted children did not differ significantly from the difference scores for the normal hearing children.

Stacy et al. [14] studied different factors, including auditory performance, communication skills, educational progress, life quality, and cochlear-implanting performance, influencing the lives of English children with auditory impairments. It was observed that cochlearimplanted children without other disabilities were better than those with auditory damages and side disabilities. In many aspects, good performance was associated with factors such as age, gender, average auditory performance, high-educated parents, and appearance of the disorder after the age of 3 years. The children with implants before the age of 5 years, with a minimum of 4 years passed from the operation, showed good performance in all aspects. Generally, the results showed that those children that were implanted before the age of 5 years had better performance in communication skills, speaking, education, and life quality.

Calms et al. [15] studied speech perception and speech intelligibility in children with auditory damages after cochlear-implantation. Sixty-three implanted children with pre-lingual deafness and up to 5 years of age participated in the study. The implantation was done before the children attained 10 years of age. Auditory perceptions were evaluated using TEPP ${ }^{1}$, and speech intelligibilities were classified according to the $\mathrm{SIR}^{2}$. The results showed that congenitally and prelingually deaf children who received cochlear implant before the age of 10 years developed speech perception and speech intelligibility abilities.

The closed-set perception progressed quickly and seemed to reach a plateau at 5 years post implantation. The improvement of open-sentence perception was not significant until the first year post implantation. The speech intelligibility improved regularly for the first five-year post implantation. Different research studies showed an improvement post-transplantation in the case of children suffering from auditory damages, auditory perception, and speech intelligibility.

However, the relationship between (short-term and working) memory performance and auditory perception

1. Test for the Evaluation of Voice Perception and Production (TEPP)

2. Speech Intelligibility Rating (SIR) and speech intelligibility was not studied. In addition, the performance of short-term memory of cochlear-implanted children was significantly weaker than that in normal children. Hence, this research aimed at studying the relationship between auditory perception and speech intelligibility, and working memory and short-term memory in cochlear-implanted children.

\section{Methods}

\section{Methodology}

Based on the objective, the research study is an applied research. Based on its data collection techniques, it is a nonexperimental, correlational and causal-comparative study.

\section{Statistical population}

The statistical population includes two subgroups:

1) All school-age [7-13] cochlear-implanted children who visited Rasul Akram Auditory Center in Tehran between August 2011 and August 2012.

2) Normal school children in primary schools of region 6 in Tehran during 2011-2012.

\section{Statistical sample and sampling method}

The sample included 31 cochlear-implanted children (16 girls and 15 boys). Convenient sampling was used to select the children for this study due to the limitations of the implant centers. In addition, 31 normal children (16 girls and 15 boys) were randomly selected as the comparison group in memory performance section. The sample inclusion criteria included: deep bilateral pre-lingual hearing drop; passage of at least 3 years (36 months) from the implant; normal parents; normal intelligence; no side disability (mental backwater, brain paralysis, growth learning disorders, behavioral and emotional disorders, vision impairments, etc.); and studying in normal primary schools.

\section{Research instrumentation}

The Categories of Auditory Performance (CAP), a hierarchical scale, was used to evaluate the auditory performance of a child in different real-life situations. CAP was developed by Archbold et al. [2] and was revised in 1998. High inter-rater reliability estimates have produced a good reliability in the case of implanted children. This scale is an index of eight components from easy to hard. This is a valid test and can provide additional support for the advantage of cochlear-implant in children. This 
test was administered to 33 participants from Satemton University and was recorded by six films. The results showed high reliability The total inter-rater reliability was 0.76 with 0.05 level of significance. This scale has been translated into different languages. Also, the SIR test, was developed by Allen et al. [3] and used to scale speech intelligibility. This index was constructed to evaluate speeches of children based on five points.

The working memory set was used for evaluating the working memory in children. This test was also used to measure short-term memory, so that recall of forward numbers tests and cubes was considered to measure the short-term memory. However, the whole test was administered to measure the working memory.

\section{Procedure}

The sampling was done based on the enrollment criteria. Prior to this, a briefing session was held to describe the goals of the research. After obtaining the parental consent and reviewing the children's profiles, CAP was performed to ensure their normal intelligence and the absence of any additional disabilities. Also, SIR was used to measure speech intelligibility. Then two short-term memories and working memory tests were executed (WMTB-C test). Finally, the samples were randomly selected from primary schools of region 6 of Tehran (2 boys' schools and 2 girls' schools).

\section{Results}

With regard to Table 1, the performance of the group with auditory impairments was poorer than the normal group in memory items. In addition, the mean and SD of working memory for cochlear-implanted children were 53.13 and 8.628, respectively, in comparison to the nor- mal children with a mean and SD of 68.90 and 10.669, respectively. This indicates the weaker performance of the cochlear-implanted children. Also, the mean and SD for short-term memory of cochlear-implanted children was 47.10 and 6.569, respectively, which indicates the weaker performance of cochlear-implanted children, than normal children with mean and SD of 56.13 and 6.691 , respectively.

Table 2 shows the covariance between the groups. Regarding the level of significance, there is no significant difference between covariance matrices; therefore, Wilks's Lambda Test is considered suitable.

Since the results in Table 3 are not significant with a significance level of $0.05(\mathrm{P}>0.05)$, the homogeneity principle is valid for the variances in two groups of hearing damages and normal.

Table 4 shows the Wilks's multi-variable variance analysis (MANOVA). This test shows that the two hearing damaged and normal groups are significantly different at least in one of the dependent variables.

According to Table 5, we observe that both groups are different in all four dependent variables. Finally, to clarify the differences between groups, we referred to Table 1 and found that the performances of normal children by all variables are weaker than those for auditory damages.

MANOVA was performed to find out whether there is any difference in memory performances of both groups $(\mathrm{P}=0.001, \mathrm{~F}=7.683, \mathrm{v}=0.650)$, which indicated a significant difference; namely, children with auditory damages had weaker memory performances than normal children

Table 1. Mean and standard deviation of working and short-term memory in hearing impaired and normal hearing children.

\begin{tabular}{|c|c|c|c|c|}
\hline & Hearing situation & Mean & SD & $\mathbf{N}$ \\
\hline \multirow{3}{*}{ Working memory score } & Hearing impaired & 57.13 & 8.628 & 31 \\
\hline & Normal & 68.90 & 10.669 & 31 \\
\hline & Total & 63.02 & 11.306 & 62 \\
\hline \multirow{3}{*}{ Working memory span } & Hearing impaired & 3.6084 & 0.47684 & 31 \\
\hline & Normal & 4.0939 & 0.64574 & 31 \\
\hline & Total & 3.7873 & 0.64222 & 62 \\
\hline \multirow{3}{*}{ Short-term memory score } & Hearing impaired & 47.10 & 6.569 & 31 \\
\hline & Normal & 56.13 & 6.961 & 31 \\
\hline & Total & 51.61 & 8.111 & 62 \\
\hline \multirow{3}{*}{ Short-term memory span } & Hearing impaired & 3.8710 & 0.54723 & 31 \\
\hline & Normal & 4.6290 & 0.61870 & 31 \\
\hline & Total & 4.2500 & 0.69394 & 62 \\
\hline
\end{tabular}


Table 2. Box's test of equality of covariance matrices.

\begin{tabular}{ccc}
\hline Box's M & $\mathbf{1 2 . 5 3 3}$ \\
\hline F & 1.163 \\
df1 & 10 \\
df2 & 17211.155 \\
Sig. & 0.311 \\
\hline
\end{tabular}

Table 3. Multivariate tests.

Iranian Rehabilitation Journa

\begin{tabular}{cccccccc}
\hline \multirow{2}{*}{ Effect } & Value & F & Hypothesis df & Error df & Sig. & Partial eta squared \\
\hline \multirow{3}{*}{ Deaf normal } & Pillai's trace & 0.350 & 7.683 & 4.000 & 57.000 & 0.001 & 0.350 \\
& Wilks' lambda & 0.650 & 7.683 & 4.000 & 57.000 & 0.001 & 0.350 \\
& Hotelling's trace & 0.539 & 7.683 & 4.000 & 57.000 & 0.001 & 0.350 \\
& Roy's largest root & 0.539 & 7.683 & 4.000 & 57.000 & 0.001 & 0.350 \\
\hline
\end{tabular}

Table 4. Multivariate tests.

Iranian Rehabilitation Journal

\begin{tabular}{ccccc}
\hline & F & df1 & df2 & Sig. \\
\hline Working memory score & 0.459 & 1 & 60 & 0.501 \\
Working memory span & 1.606 & 1 & 60 & 0.210 \\
Short-term memory score & 0.047 & 1 & 60 & 0.828 \\
\hline Short-term memory span & 0.036 & 1 & 60 & 0.850 \\
\hline
\end{tabular}

Iranian Rehabilitation Journal

Table 5. Tests of between-subjects effects.

\begin{tabular}{cccccccc}
\hline Source & Dependent variable & $\begin{array}{c}\text { Type III sum of } \\
\text { squares }\end{array}$ & Df & $\begin{array}{c}\text { Mean } \\
\text { square }\end{array}$ & F & Sig. & $\begin{array}{c}\text { Partial eta } \\
\text { squared }\end{array}$ \\
\hline \multirow{5}{*}{ Deaf normal } & Working Memory score & 2148.790 & 1 & 2148.790 & 22.826 & 0.001 & 0.276 \\
& $\begin{array}{c}\text { Short-term Memory } \\
\text { score }\end{array}$ & 1264.516 & 1 & 1264.516 & 27.608 & 0.001 & 0.315 \\
& $\begin{array}{l}\text { Working Memory span } \\
\text { Short-term Memory } \\
\text { span }\end{array}$ & 5.829 & 1 & 5.829 & 18.092 & 0.001 & 0.232 \\
& & 8.907 & 1 & 8.907 & 26.111 & 0.001 & 0.303 \\
\hline
\end{tabular}

Table 6. Spearman's rho correlation.

Iranian Rehabilitation Journa

\begin{tabular}{|c|c|c|c|c|c|c|c|c|c|c|c|c|}
\hline & \multicolumn{3}{|c|}{ Working memory score } & \multicolumn{3}{|c|}{$\begin{array}{c}\text { Working memory } \\
\text { span }\end{array}$} & \multicolumn{3}{|c|}{$\begin{array}{l}\text { Short-term memory } \\
\text { score }\end{array}$} & \multicolumn{3}{|c|}{$\begin{array}{c}\text { Short-term memory } \\
\text { span }\end{array}$} \\
\hline & 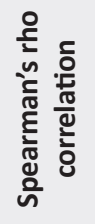 & $\dot{00}$ & $z$ & 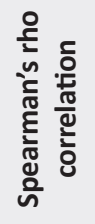 & $\stackrel{00}{\omega}$ & $z$ & 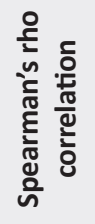 & $\dot{\omega n}$ & $z$ & 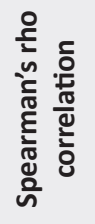 & $\dot{n}$ & $z$ \\
\hline $\begin{array}{l}\text { Auditory per- } \\
\text { ception }\end{array}$ & 0.727 & 0.001 & 31 & 0.641 & 0.001 & 31 & 0.675 & 0.001 & 31 & 0.681 & 0.001 & 31 \\
\hline $\begin{array}{l}\text { Speech intel- } \\
\text { ligibility }\end{array}$ & 0.859 & 0.001 & 31 & 0.677 & 0.001 & 31 & 0.840 & 0.001 & 31 & 0.705 & 0.001 & 31 \\
\hline
\end{tabular}


According to Table 6, the relationship between auditory perception with working memory and short-term memory is significant by $\mathrm{P}=0.001$. Also, the relationship between speech intelligibility with working memory and short-term memory is significant by $\mathrm{P}=0.001$.

As you see, there is a positive and significant relation between the scores of memory and auditory perception and between memory and speech intelligibility that refers to the auditory perception and speech intelligibility scores to increase with an increase in memory scores.

\section{Discussion}

Auditory skills that have grown by implanting may affect abilities of children in learning words and semantics of grammatical structures. Language growth of children with auditory damages is an important step to develop educational and life facilities for them [5]. In addition, it can be said that the route to language production naturally requires memorizing and ordering linguistic data. This data includes a broad spectrum of levels including message level (intentions of the speaker), words in expression, expressions in sentences, and productive movements for speech execution. Language production needs interaction of all representation levels that engages in working memory [18]. One step of speech production is encoding phonemes, in which a word is determined as the phoneme sequence for production. This process is the middle step between word selection and its production. Studies in encoding phonemes indicate that some findings are compatible with the performance of active memory. The analysis of speech errors also showed that many recurrent phenomena that relate to phonemic encoding are used for saving data in working memory. For example, probability of occurrence of speech errors in similar phonemes is more than when there are no similar phonemes.

One of the limitations of this study is that the instrumentation was not normalized. Another limitation is unsuitability of some sub-tests for working memories of children with auditory damages, which necessarily caused deletion of these sub-tests. The small size of the sample also affects the generalization of findings. Nevertheless, some limitations come from its design, time, and location. Therefore, it is proposed to conduct other research studies in this area in three forms:

- Complete replication (duplicate research by this researcher).

- Real replication (duplicate research by others using these scales).
- Systematic replication (duplicate research on another population with other scales).

\section{Conclusion}

Since low-hearing affects language growth and communication skills of children by creating communication problems and social and cognitive symptoms, the goal of this research was to study the relationship between working and short-term memories with auditory perception and speech intelligibility in cochlear-implanted children. Another goal of this research was to compare the status of working and short-term memories between the cochlear-implanted and normal children.

The results showed that cochlear-implanted children had weaker performance in working memory and shortterm memory than the normal children. These results are compatible with those of Akbarlu [6] William and Libert [11], and Dawson et al. [13]. Working memory and shortterm memory were found to be compatible in cochlearimplanted and normal children. Implanting in lower ages brings about the improvement of working and short-term memories in those without implantation; however, they cannot be compared with normal children due to their implant age and use of rest of their hearing sense. Hassanzadeh et al. [16] studied the role of age on auditory perception of cochlear-implanted children and found that the lower the age at operation, the better was the auditory perception and speech intelligibility. Researchers and physicians believed that although implanting affected the promotion of speech intelligence and cognitive growth, it is advisable to do the operation in lower ages.

The results of the current research showed that there was a positive and significant relationship between auditory perception and working and short-term memories of cochlear-implanted children. Also, there was a positive and significant relationship between speech intelligibility and working and short-term memories of cochlear-implanted children. These findings are compatible with the results of Ibertson et al. [10], Philips et al. [12], Dawson et al. [13], and Burkhoder et al. [17]. It can be said that although the growth levels of auditory skills in cochlearimplanted children are different, there is a background for creation of production patterns.

\section{Acknowledgements}

The article is extracted from Ms. Soheyla Talebi's Master thesis in the Department of Psychology of Exceptional Children, University of Tehran, Tehran, Iran. 


\section{Conflict of Interests}

The authors declared no conflict of interests.

\section{References}

[1] Pickering S, Gathercole S. Working memory test battery for children (WMTB-C). Oxford: Pearson Publication; 2001.

[2] Archbold S, Lutman ME, Marshall DH. Categories of Auditory Performance. The Annals of Otology, Rhinology \& Laryngology. 1995; 166:312-14

[3] Allen MC, Nikolopoulos TP, O'Donoghue GM. Speech intelligibility in children after cochlear implanation. Otology \& Neurotology. 1998; 19(6):742-46.

[4] Afrooz G. [An introduction to psychology and education of exceptional children (Persian)]. 27 $7^{\text {th }}$ ed. Tehran: University of Tehran Publication; 2010

[5] Hassanzadeh S. [Psychology and education of deaf children (Persian)]. Tehran: Samt Press; 2009.

[6] Akbarloo N. [Auditory Perception of severely hearing impaired students in deaf and regular primary schools (Persian)]. Journal of Exceptional Children. 2007; 7(1):61-78.

[7] Mendel LL, Danhauer JL. Audiologic evaluation and management and speech perception assessment. Oxford: Singular Publishing Group; 1997.

[8] Arjmandnia A, Seifenaraghi M. Effect of rehearsal on working memory performance in dyslexic students. Journal of Behavioral Sciences. 2009; 3(3):173-78.

[9] Chin SB, Bergeson TR, Phan J. Speech intelligibility and prosody production in children with cochlear implants. Journal of Communication Disorders. 2012; 45(5):355-66.

[10] Ibertsson T, Hansson K, Asker-Àrnason L, SahlÉn B. Speech recognition, working memory and conversation in children with cochlear implants. Deafness \& Education International. 2009; 11(3):132-51.

[11] Willems P, Leybaert J. Phonological Short term memory in deaf children fitted with a cochlear implant: effects of phonological similarity, word lenght and lipreading cues. Revista de Logopedia, Foniatría y Audiología. 2009; 29(3):174-85.

[12] Phillips L, Hassanzadeh S, Kosaner J, Martin J, Deibl M, Anderson I. Comparing auditory perception and speech production outcomes: non-language specific assessment of auditory perception and speech production in children with cochlear implants. Cochlear Implants International. 2009; 10(2):92-102.

[13] Dawson PW, Busby PA, McKay CM, Clark GM. Short-term auditory memory in children using cochlear implants and its relevance to receptive language. Journal of Speech, Language, and Hearing Research. 2002; 45(4):789-801.

[14] Stacey PC, Fortnum HM, Barton GR, Summerfield AQ. Hearing-impaired children in the United Kingdom, I: auditory performance, communication skills, educational achievements, quality of life, and cochlear implantation. Ear and Hearing. 2006; 27(2):161-86.
[15] Calmels MN, Saliba I, Wanna G, Cochard N, Fillaux J, Deguine $\mathrm{O}$, et al. Speech perception and speech intelligibility in children after cochlear implantation. International Journal of Pediatric Otorhinolaryngology. 2004; 68(3):347-51.

[16] Hassanzadeh S, Farhadi M, Daneshi A, Emamjomeh H The effects of age on auditory speech perception development in cochlear-implanted prelingually deaf children. Otolaryngology-Head and Neck Surgery. 2002; 126(5):524-27.

[17] Burkholder RA, Pisoni DB. Speech timing and working memory in profoundly deaf children after cochlear implantation. Journal of Experimental Child Psychology. 2003; 85(1):63-88

[18] Acheson DJ, MacDonald MC. Verbal working memory and language production: common approaches to the serial ordering of verbal information. Psychological Bulletin. 2009; 135(1):50-68. 
